\title{
Coaxially Aligned Polyaniline Nanofibers Doped with 3-Thiopheneacetic Acid through Interfacial Polymerization
}

\author{
Lixia Zhang, ${ }^{1}$ Geoffrey I. N. Waterhouse, ${ }^{2}$ and Lijuan Zhang ${ }^{2}$ \\ ${ }^{1}$ College of Chemistry and Life Science, Guangxi Teachers Education University, Nanning 530001, China \\ ${ }^{2}$ School of Chemical Sciences, The University of Auckland, Auckland 1142, New Zealand \\ Correspondence should be addressed to Lijuan Zhang, zhang.lijuan@hotmail.com
}

Received 17 January 2011; Revised 28 April 2011; Accepted 22 May 2011

Academic Editor: Zhi Li Xiao

Copyright ( 2011 Lixia Zhang et al. This is an open access article distributed under the Creative Commons Attribution License, which permits unrestricted use, distribution, and reproduction in any medium, provided the original work is properly cited.

\begin{abstract}
Coaxially aligned polyaniline (PANI) nanofibers doped with 3-thiopheneacetic acid (TAA) were chemically synthesized by the interfacial polymerization of aniline in the presence of TAA, using iron (III) chloride hexahydrate $\left(\mathrm{FeCl}_{3} \cdot 6 \mathrm{H}_{2} \mathrm{O}\right)$ as the oxidant. The morphology, crystallinity, room temperature conductivity, and coaxial alignment of the PANI-TAA nanofibers were highly dependent on the organic solvent used for the interfacial polymerization, the oxidant, and also the molar ratio of the aniline to TAA. Hexane, diethyl ether, dichloromethane, chloroform, and acetone were used as the organic solvents, and chloroform proved to be the best solvent for the formation of PANI-TAA nanofibers. The redox potential of the oxidant is the key to controlling the morphology and diameter of the PANI-TAA nanofibers. The use of $\mathrm{FeCl}_{3}$ as the oxidant leads to the formation of thin ( $\left.\sim 50 \mathrm{~nm}\right)$ PANI-TAA nanofibers, which increased in length, crystallinity, conductivity, and coaxial alignment as the molar ratio of TAA to aniline was increased from $0.1: 1$ to $1: 1$. By comparison, only granular PANI was obtained when ammonium persulfate (APS), which has a higher redox potential, was used as the oxidant. The doping function of TAA in the PANI-TAA nanofibers was confirmed by means of FTIR and UV-Visible spectroscopy.
\end{abstract}

\section{Introduction}

Polyaniline (PANI) has attracted a lot of attention in the conducting polymer field due to its electrical, electrochemical, optical, and environmental stability [1], and it has been extensively studied for many potential applications including lightweight battery electrodes [2, 3], electromagnetic shielding devices [4], anticorrosion coatings [5], and sensors [6]. With the development of nanoscience and nanotechnology, researchers now focus on the nano-sized forms of polyaniline for applications in actuators [7], drug delivery systems [8], tissue engineering [9], gas sensors, and biosensors [10]. Nanostructured PANI can be synthesized by a variety of different methods, such as template synthesis $[11,12]$, interfacial polymerization [13], self-assembly process [14], and electrospinning method [15]. Among these methods, the template synthesis [12] and electrospinning method [16] are the preferred and most reliable routes for synthesizing ordered conducting polymer nanostructures. However, the templating approach is comparatively expensive since postpolymerization steps are required to remove the template.
The electrospinning method requires a high pressure source and good polymer solubility which limits its general applicability. Interfacial polymerization is one of the most effective alternative methods to chemically synthesize nanostructured electronic conducting polymers [13, 17]. The interfacial polymerization method is based on the polymerization of a monomer at the interface of two immiscible liquids [18] and has previously been successfully used to synthesize PANI nanoneedles [19], nanofibres [20], and cyclic nanostructures [21]. Interfacial polymerization is a nontemplate approach in which high local concentrations of both monomer and dopant anions at the liquid-liquid interface promote the formation of monomer-anion (or oligomer-anion) aggregates that act as nucleation sites for polymerization. Typically interfacial polymerization produces powders with fibrillar morphology. Since polymerization occurs only at the liquidliquid interface, a small zone of well defined geometry, different types of nanostructures may form depending on the properties of the two immiscible solvents. However, few reports have appeared in the literature examining the effect 
of solvent interfacial phenomena on conducting polymer morphology.

Thiophene derivatives are chemically stable compounds and easy to process [22], which has led to their widespread use in modern drug design, biodiagnostics, electronic and optoelectronic devices, and conductive polymers [23]. 3thiopheneacetic acid possesses a thiophene ring and also a hydrophilic $-\mathrm{COOH}$ group. Accordingly, it is expected that 3 -thiopheneacetic acid can be used as dopant to prepare conductive PANI nanofibers whilst at the same time bringing the other desirable properties of thiophene (such as improved solubility in organic solvents).

Herein we report the successful synthesis of coaxially aligned PANI nanofibers with an average diameter of $50 \mathrm{~nm}$ and length greater than $1 \mu \mathrm{m}$ by the interfacial polymerization of aniline in the presence of TAA (the dopant), using iron (III) chloride hexahydrate $\left(\mathrm{FeCl}_{3} \cdot 6 \mathrm{H}_{2} \mathrm{O}\right)$ as the oxidant. The morphology of PANI-TAA nanofibres is controlled by careful selection of the oxidant, organic and molar ratio of TAA to aniline in the reaction solution. The structural features of the PANI-TAA nanofibers were characterized by UV-Vis, FTIR spectra, and powder XRD.

\section{Experimental}

2.1. Reagents. Aniline (An) and 3-thiopheneacetic acid (TAA) were purchased from Aldrich Chemical Co. Iron chloride hexahydrate $\left(\mathrm{FeCl}_{3} \cdot 6 \mathrm{H}_{2} \mathrm{O}\right)$, hexane, diethyl ether, dichloromethane, chloroform, and acetone were all of reagent grade (>99\%) and purchased from Sinopharm Chemical Reagent Beijing Co., Ltd. Aniline was distilled under reduced pressure prior to use and stored under $\mathrm{N}_{2}$. Other reagents were used directly as supplied by the manufacturer.

2.2. Synthesis of PANI-TAA Nanofibers. The PANI-TAA nanofibers were synthesized by interfacial polymerization in the presence of TAA as the dopant and $\mathrm{FeCl}_{3} \cdot 6 \mathrm{H}_{2} \mathrm{O}$ as the oxidant. Using chloroform as the organic solvent, the typical synthesis procedure for the nanofibers was as follows: $2 \mathrm{mmol}$ of aniline and a certain molar amount of TAA $(0.02-0.2 \mathrm{mmol})$ were dissolved in $10 \mathrm{~mL}$ chloroform. $\mathrm{FeCl}_{3}$ $(10 \mathrm{mmol})$ was dissolved in $5 \mathrm{~mL}$ of deionized water. The $\mathrm{FeCl}_{3}$ solution was then carefully added to the chloroform solution with minimal agitation along the side of the beaker. The aniline/3-thiopheneacetic/chloroform formed the lower organic layer and the $\mathrm{FeCl}_{3}$ solution formed the upper aqueous layer. The 2-phase reaction mixture was left undisturbed for $\sim 12 \mathrm{~h}$ at room temperature. With time, the upper aqueous layer became brown, then dark green. The resulting PANI-TAA precipitate in the upper aqueous layer was then collected and washed repeatedly with water, methanol and diethyl ether. Finally, the product was dried under vacuum at room temperature for 24 hours.

2.3. Characterization. The morphologies of the PANI-TAA nanomaterials were examined using a JEOL JSM-6700F field emission scanning electron microscope (SEM). Before SEM analysis, samples were mounted on aluminum studs using double-sided adhesive graphite tape and sputter-coated with platinum. The electronic and molecular structure of the PANI-TAA specimens was characterized by UV-visible and FTIR spectroscopy, as well as powder X-ray diffraction (XRD). The UV-visible absorbance spectra of the PANI-TAA products dissolved in $m$-cresol were recorded from 300 to $1200 \mathrm{~nm}$ on a Hitachi UV3100 spectrometer. FTIR spectra of the PANI-TAA nanofibers were collected on a Bruker EQUINOX55 over the range $4000-400 \mathrm{~cm}^{-1}$ at $4 \mathrm{~cm}^{-1}$ resolution. XRD patterns were obtained at room temperature on D/max-2400 spectrometer. The room-temperature conductivity of compressed pellets of the PANI-TAA nanofibers was measured by a standard four-probe conductivity meter (Jandel Model RM2). The electrochemical response of the PANITAA materials was determined using a Zhengzhou Shiruisi Instrument Technology Co. Ltd. RST3100 electrochemical workstation. The sample was first dispersed in $\mathrm{CHCl}_{3}$ and the dispersion slowly added dropwise onto a $2 \mathrm{~mm}$ diameter gold plate working electrode to form a film which was allowed to dry at room temperature. The cell was filled with $0.1 \mathrm{M} \mathrm{HCl}$ and purged with $\mathrm{N}_{2}$ for approximately $10 \mathrm{~min}$. Following this, a $\mathrm{N}_{2}$ was flowed over the solution to prevent $\mathrm{O}_{2}$ from reentering the cell for the remainder of the experiment. Cyclic voltammograms were recorded in the potential range from -500 to $+1000 \mathrm{mV}$ at scan rates of 20 to $120 \mathrm{mV} \mathrm{s}^{-1}$, using a saturated calomel electrode (SCE) as a reference electrode and a Pt wire as a counterelectrode.

\section{Result and Discussion}

For the interfacial polymerization at a liquid/liquid interface, the choice of solvents is very important though not well documented in the literature. In order to find the most suitable organic solvent for the interfacial polymerization of PANI-TAA nanofibres, five different organic solvents (hexane, ether, dichloromethane, chloroform, and acetone) were selected and investigated. Among these solvents, chloroform was found to be the best solvent for yielding PANI-TAA nanofibres with good aspect ratios (length: diameter $>20$ under certain conditions). Other reaction parameters such as the reaction temperature, the reaction time, the type of the oxidant, the molar ratio of oxidant to aniline, and the molar ratio of TAA to aniline were investigated. We found that the reaction temperature has no obvious effect on the formation of orderly PANI-TAA nanofibers. When the reaction time was $>12$ hours, no obvious effect of reaction time on the PANI-TAA nanofibers was observed, reflecting the fact that the reaction had proceeded to completion after 12 hours. The type of oxidant had a most important influence on the morphology of PANI-TAA nanofibers. Figures $1(\mathrm{a})$ and $1(\mathrm{~b})$ show SEM images for PANI-TAA nanofibers obtained using $\mathrm{FeCl}_{3}$ and APS as the oxidant, respectively. Only granular PANI-TAA was observed when the APS was used as the oxidant (Figure 1(b)). By comparison, when $\mathrm{FeCl}_{3}$ was used as the oxidant, both granular and nanofiber PANI-TAA formed (Figure 1(a)). Based on this preliminary result, we investigated the influence of the molar ratio of TAA to aniline on the formation of PANI-TAA nanofibers. Figure 2 shows SEM images of PANI-TAA nanofibers obtained at different molar ratios of TAA to aniline. From the SEM images, 


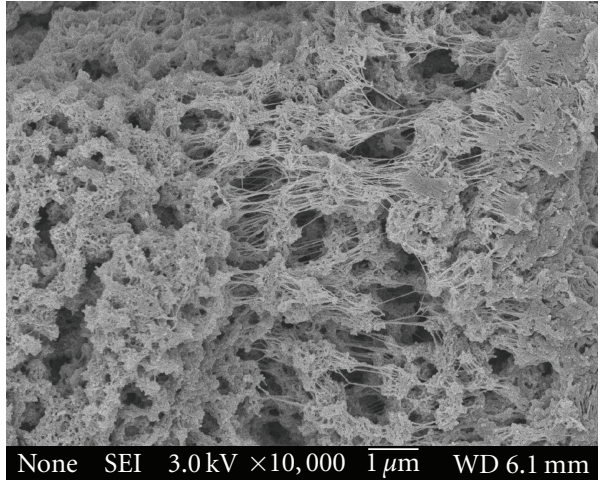

(a)

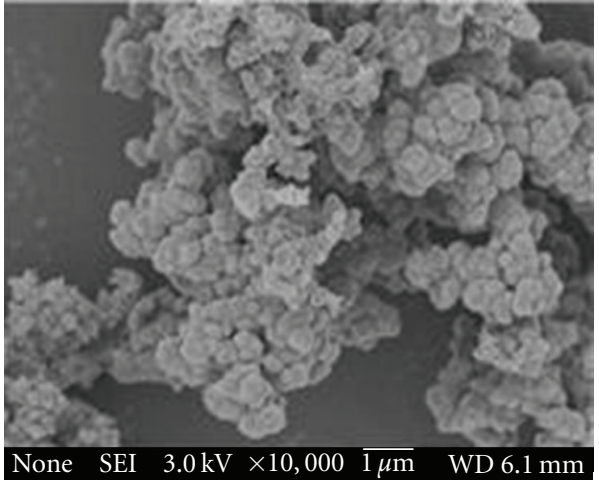

(b)

FIgURE 1: SEM images of PANI-TAA synthesized in water/chloroform solutions using different oxidants: (a) $\mathrm{FeCl}_{3}$ and (b) APS. Other reaction conditions were $\mathrm{An}=0.2 \mathrm{M}, \mathrm{TAA} / \mathrm{An}=0.1: 1, \mathrm{FeCl}_{3} / \mathrm{An}=5, \mathrm{APS} / \mathrm{An}=1$, and reaction time $=12 \mathrm{~h}$.

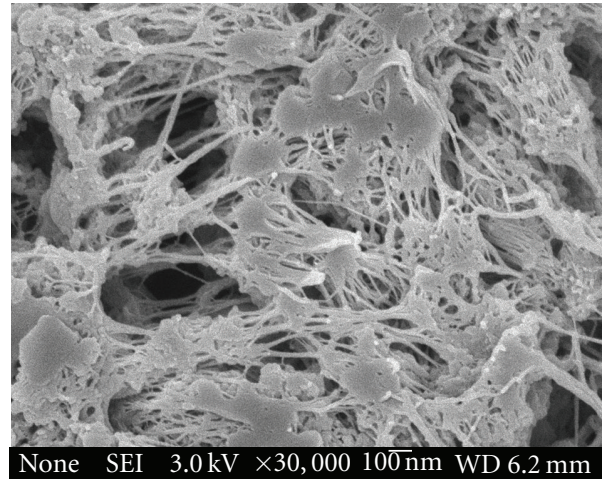

(a)

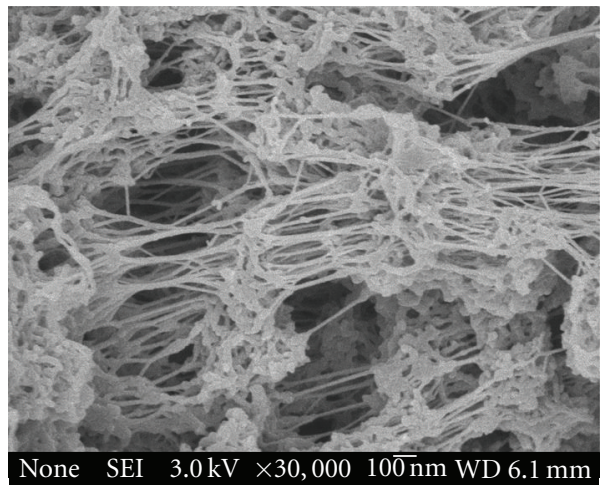

(c)

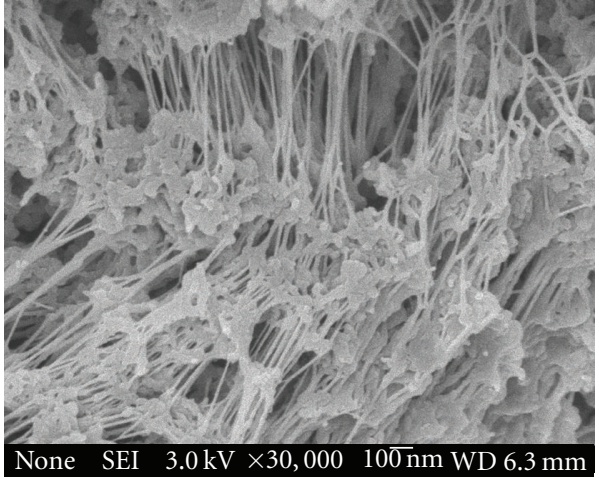

(b)

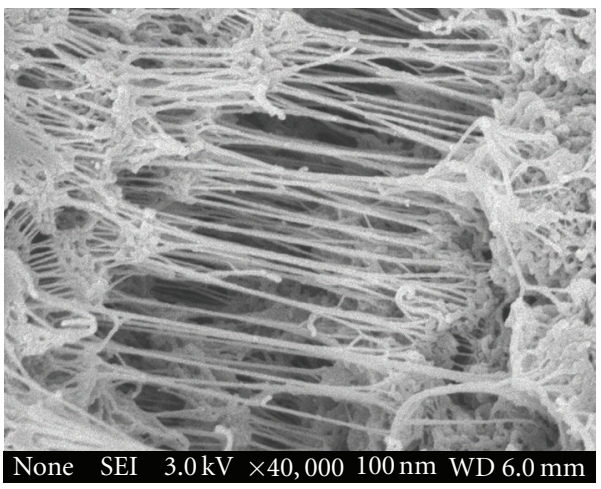

(d)

FIgURE 2: SEM images of PANI-TAA synthesized in water/chloroform solutions at different molar ratios of TAA to An: (a) $0.1: 1$, (b) $0.5: 1$, (c) $0.8: 1$, and (d) $1: 1$. Other reaction conditions were $\mathrm{An}=0.2 \mathrm{M}, \mathrm{FeCl}_{3} / \mathrm{An}=5$, and reaction time $=12 \mathrm{~h}$.

we can conclude that the length and coaxial alignment of the PANI-TAA nanofibers can be controlled in part by simply varying the molar ratio of TAA to aniline. The diameter and length of the PANI-TAA nanofibers are $\sim 50 \mathrm{~nm}$ and $300 \mathrm{~nm}$, respectively, when the molar ratio of TAA to aniline is $0.1: 1$. The length of PANI-TAA nanofibers increased with an increase of the molar ratio of TAA to aniline and reached a length $>1 \mu \mathrm{m}$ when the molar ratio of TAA to aniline was $1: 1$. Also, the coaxial alignment of PANI-TAA nanofibers increased with the increase of the molar ratio of TAA to aniline, which can be clearly seen in Figure 2(d). The increase in the length of the PANITAA nanofibres with increasing TAA: aniline ratio might be expected to increase the crystallinity of the materials. In order to verify this, powder XRD patterns were collected for the PANI-TAA nanofibers obtained at different molar 
ratios of TAA: An (Figure 3). The XRD patterns for all samples contained six peaks centred around at $2 \theta=6.74^{\circ}$, $9.68^{\circ}, 14.94^{\circ}, 20.56^{\circ}, 25.34^{\circ}$, and $27.2^{\circ}$, all of which are characteristic for nanocrystalline PANI. The first peak at $2 \theta$ $=6.74^{\circ}$ (corresponding to d-spacing of $13.1 \AA$ ) is assigned to the periodic distance between the dopant and $\mathrm{N}$ atom on adjacent main chains [24], whereas the second peak at $2 \theta=9.68^{\circ}$ (corresponding to d-spacing of $9.1 \AA$ ) and the third peak at $2 \theta=14.94^{\circ}$ (corresponding to d-spacing of $5.9 \AA$ ) are attributed to parallel repeat units of PANI and the interplanar distance followed by the inclusion of TAA molecules $[25,26]$, respectively. Interestingly, these three peaks became sharper and shifted slightly to smaller $2 \theta$ angles when the molar ratio of TAA to An changed from $0.1: 1$ to $1: 1$. The first peak shifted from $2 \theta=6.74^{\circ}$ to $6.32^{\circ}$ (corresponding to d-spacing of $14.0 \AA$ ), the second peak shifted from $2 \theta=9.68$ to $9.14^{\circ}$ (corresponding to d-spacing of $9.7 \AA$ ), and the third peak shifted from $2 \theta=14.94^{\circ}$ to $14.76^{\circ}$ (corresponding to d-spacing of $6.0 \AA$ ) (Figure $3(\mathrm{~d})$ ). These changes are significant and suggest that increasing the molar ratio of TAA to aniline results in increasing the distance in the direction perpendicular to the polymer chain. The peaks at $2 \theta=20.56^{\circ}$ and $25.34^{\circ}$, which are usually ascribed to the periodicity parallel and perpendicular to the polymer chains of PANI [27], as well as the peak at $2 \theta=27.2^{\circ}$ assigned to a periodicity caused by $\mathrm{H}$-bonding between PANI chains [28], are observed in all PANI-TAA preparations (see Figures $3(a)-3(d)$ ). These results suggested that $\mathrm{H}$-bonding of amine groups on the PANI backbone and electrostatic interactions between adjacent polymer chains results in the preferential orientation of polymer chains, leading to oriented nanofibers. The XRD patterns observed for the PANI-TAA samples are very similar to those reported for the PANI nanotubes synthesized in aqueous solution [29], indicating that there is close structural similarity between the PANI-TAA nanofibres synthesized here by interfacial polymerisation and PANI nanofibres/nanotubes synthesized by conventional bulk polymerization methods.

The PANI-TAA nanofibres were characterized by FTIR and UV-Vis spectroscopy to confirm their composition. FTIR transmittance spectra for PANI-TAA nanofibers synthesized at the different molar ratios of TAA to An are shown in Figure 4. Most of the peaks in the FTIR spectra can be assigned to doped PANI. For instance, the main peak at $1584 \mathrm{~cm}^{-1}$ is characteristic of the quinone diimine ring-stretching deformation, while the $1500 \mathrm{~cm}^{-1}$ band indicates benzenoid diamine ring-stretching [30]. The broad band centred about $3440 \mathrm{~cm}^{-1}$ corresponds to the free $\mathrm{N}-$ $\mathrm{H}$ stretching vibration of primary $\left(-\mathrm{NH}_{2}\right)$ and secondary amine (-NH-) groups [31, 32]. The $1300 \mathrm{~cm}^{-1}$ band is assigned to the $\mathrm{C}-\mathrm{N}$ stretching of the secondary aromatic amine [33]. The peak at $821 \mathrm{~cm}^{-1}$ is assigned to an out-ofplane deformation of $\mathrm{C}-\mathrm{H}$ in the 1,4-disubstituted benzene ring [34] and indicates that para-coupling of aniline occurs during the interface polymerization. The peak at $1246 \mathrm{~cm}^{-1}$, ascribed to the $\mathrm{C}-\mathrm{N}^{+\bullet}$ stretching vibration in the polaron structure, and the peak at $1144 \mathrm{~cm}^{-1}$ associated with the $-\mathrm{NH}^{+\bullet}=$ structure are also observed, indicating that PANI in the PANI-TAA nanofibres is in the doped state [35].

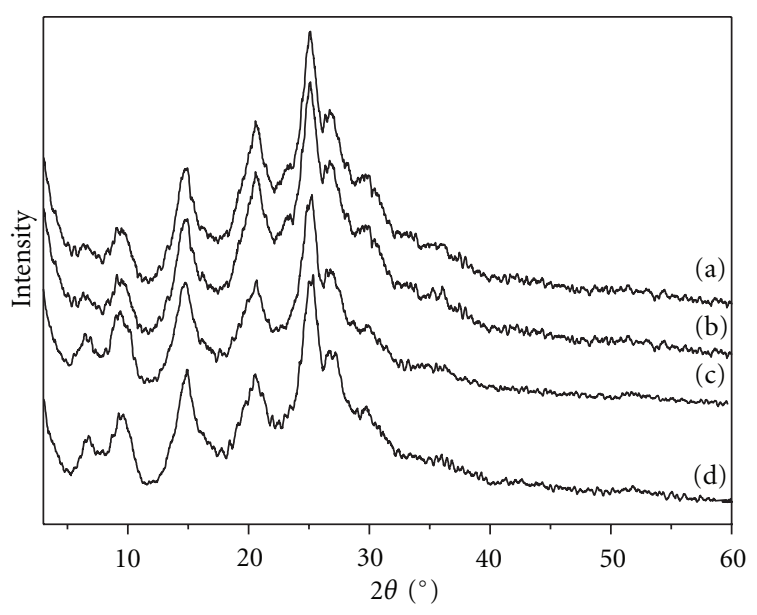

FIGURE 3: XRD patterns of PANI-TAA synthesized in water/ chloroform solutions at different molar ratios of TAA to An: (a) $0.1: 1$, (b) $0.5: 1$, (c) $0.8: 1$, and (d) $1: 1$. Other reaction conditions $\mathrm{An}=0.2 \mathrm{M}, \mathrm{FeCl}_{3} / \mathrm{An}=5$, and reaction time $=12 \mathrm{~h}$.

In addition to the characteristic peaks from PANI, peaks are observed at $1740 \mathrm{~cm}^{-1}$ (due to the $\mathrm{C}=\mathrm{O}$ group of TAA) and 2900 and $2850 \mathrm{~cm}^{-1}$ (C-H stretching vibrations of the methylene $-\mathrm{CH}_{2}-$ groups of TAA [36]). These peaks intensify with increasing TAA: aniline ratio, confirming that the TAA was successfully incorporated as a dopant into PANI-TAA.

Figure 5 shows UV-vis absorption spectra for the PANITAA nanofibers obtained at the different molar ratios of TAA to aniline. The peak at $320 \mathrm{~nm}$ is assigned to a $\pi-\pi^{*}$ excitation of the para-substituted benzene segment in PANI (-B-NH-B-NH-B-; B, benzenoid) $[34,37]$, which became more intense with the increase of the molar ratio of TAA to aniline. The peak at $450 \mathrm{~nm}$ is attributed to the excitation of the quinone diimine structure $(-\mathrm{N}=\mathrm{Q}=\mathrm{N}-; \mathrm{Q}$, quinoid $)$ in PANI [38]. A broad peak extending to over $900 \mathrm{~nm}$ is also observed and became more intense with the increase of the molar ratio of TAA to aniline. The feature is related to the charge-carrier band of PANI [39] and confirms the doping function of the TAA in the PANI nanofibers. The doping function of TAA was further confirmed by the enhancement of the room temperature conductivity of the PANI nanofibers from $5.07 \times 10^{-3} \mathrm{~S} / \mathrm{cm}$ to $1.84 \times 10^{-1} \mathrm{~S} / \mathrm{cm}$ when the molar ratio of TAA to An increased from $0.1: 1$ to $1: 1$.

The electrochemical response of the samples was investigated by cyclic voltammetry. The PANI-TAA nanofiber samples were solvent cast from a diluted dispersion onto a gold plate electrode, dried, then cycled in $0.1 \mathrm{M} \mathrm{HCl}$ at different scan rates. The resulting cyclic voltammograms are shown in Figure 6. The two sets of redox peaks are observed in agreement with the expected electrochemical behaviour of PANI [40, 41]. The oxidation process with a broad peak at approximately $+200 \mathrm{mV}$ is due to the oxidation of the leucoemeraldine to the emeraldine form of PANI, and the peak at approximately $+570 \mathrm{mV}$ is due to oxidation from the emeraldine to the pernigraniline form at a lower scan rate of $20 \mathrm{mV} \mathrm{s}^{-1}$ (black line) [41, 42]. At the higher 


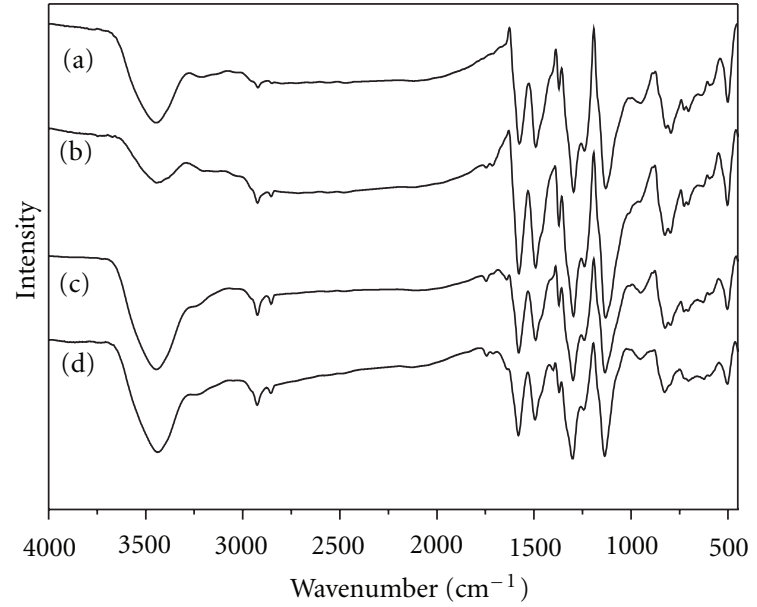

FIgURE 4: FTIR spectra of PANI-TAA synthesized in water/ chloroforms solution at different molar ratios of TAA to An: (a) $0.1: 1$, (b) $0.5: 1$, (c) $0.8: 1$, and (d) $1: 1$. Other reaction conditions $\mathrm{An}=0.2 \mathrm{M}, \mathrm{FeCl}_{3} / \mathrm{An}=5$, and reaction time $=12 \mathrm{~h}$.

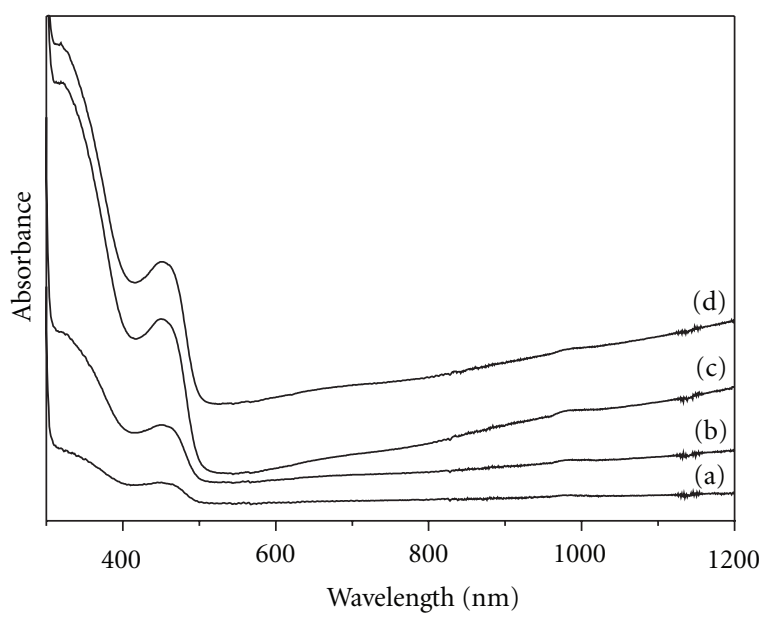

FIgURe 5: UV-Visible spectra of PANI-TAA synthesized in water/ chloroform solutions at different molar ratios of TAA to An: (a) $0.1: 1$, (b) $0.5: 1$, (c) $0.8: 1$, and (d) $1: 1$. Other reaction conditions $\mathrm{An}=0.2 \mathrm{M}, \mathrm{FeCl}_{3} / \mathrm{An}=5$, and reaction time $=12 \mathrm{~h}$.

scan rate of $120 \mathrm{mV} \mathrm{s}^{-1}$, the two sets of PANI-related peaks shifted to higher potential and the oxidation peak of the leucoemeraldine to the emeraldine form of PANI occurred around $+280 \mathrm{mV}$ and the oxidation peak from the emeraldine to the pernigraniline form was at $+628 \mathrm{mV}$ (dark yellow line).

As described in Section 2, PANI-TAA nanofibres are formed at organic solvent (chloroform)/aqueous interface and then migrate into the water layer during interfacial polymerization. Based on the previous reports [43, 44], nanofibers form initially at the liquid/liquid interface and can then become nuclei for the growth of different shaped particles depending on the $\mathrm{pH}$. Here, the aniline monomer and the oxidant are separated by the boundary between the organic and the aqueous phase, and the polymerization

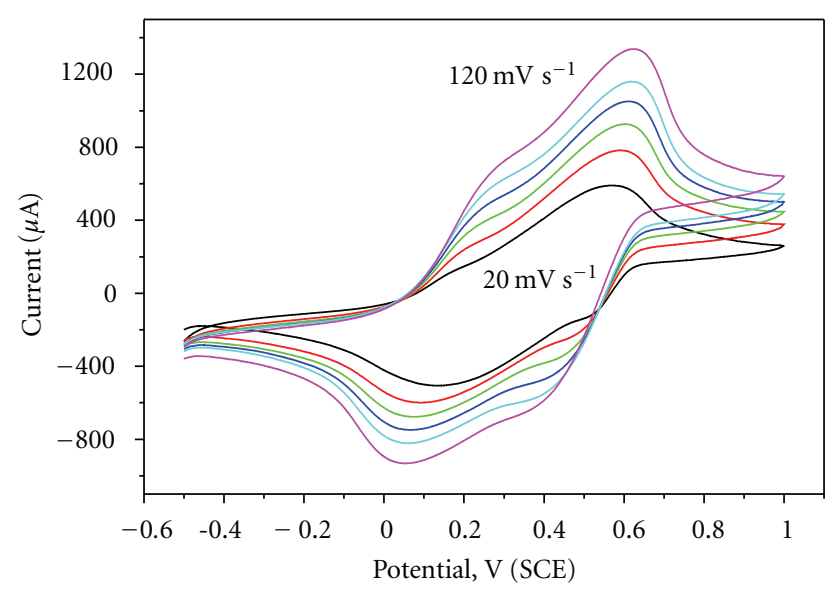

Figure 6: Cyclic voltammograms of PANI-TAA cast onto a gold plate electrode and cycled in $0.1 \mathrm{M} \mathrm{HCl}$ at scan rates of 20 to $120 \mathrm{mV} \mathrm{s}^{-1}$ (increasing in $20 \mathrm{mV} \mathrm{s}^{-1}$ ).

only takes place at the organic/aqueous interface where all the components are actually in contact, indicating that the growth direction for PANI-TAA nanofibres is very limited. Once all of the PANI has been consumed, the polymerization terminates. When APS was used as the oxidant, only granular PANI is observed (Figure 1(b)). This may be due to much rapider reaction due to the higher redox potential (2.0) of APS compared with that of $\mathrm{FeCl}_{3} \cdot 6 \mathrm{H}_{2} \mathrm{O}$ (0.7) [32]. When $\mathrm{FeCl}_{3}$ is used as the oxidant, the synergistic effect of relative narrow but well-defined growth space and slow reaction rate leads to the preferential growth of PANITAA nanofibers (Figures 1(a) and 2(a)-2(d)). The critical roles of the two immiscible solvents (chloroform and water) during interfacial polymerization, as well as the presence of TAA, on PANI nanofiber growth merit further investigation as the system provides a simple and cost effective route for the fabrication of novel coaxially aligned doped PANI nanofibres.

\section{Conclusion}

Coaxially aligned PANI-TAA nanofibers, around $50 \pm 5 \mathrm{~nm}$ in diameter and of lengths up to $1-2 \mu \mathrm{m}$, were successfully prepared by interfacial polymerization at a chloroform/water interface, using $\mathrm{FeCl}_{3}$ as the oxidant. The length, coaxial alignment, crystallinity, and electrical conductivity of the PANI-TAA nanofibers all increased with the molar ratio TAA:aniline used in the polymerization. This work extends our understanding of the formation mechanism for PANI nanofibers and will be highly useful to researchers interested in the fabrication of coaxially aligned PANI nanostructures for sensing and biomedical applications.

\section{Acknowledgments}

The paper was supported by the National Natural Science Foundation of China (no. 50573090) and the New Zealand Foundation for Science and Technology (contract no. UOAX0806). 


\section{References}

[1] A. G. Macdiarmid and A. J. Epstein, "Polyaniline: interrelationships between molecular weight, morphology, Donnan potential and conductivity," in Materials Research Society Symposia Proceedings, vol. 247, pp. 565-576, 1992.

[2] A. Wu, E. C. Venancio, and A. G. MacDiarmid, "Polyaniline and polypyrrole oxygen reversible electrodes," Synthetic Metals, vol. 157, no. 6-7, pp. 303-310, 2007.

[3] B. N. Grgur, "Polyaniline and polypyrole as cathode materials for zinc batteries in chloride and chloride/citrate based electrolytes," Journal of Advances in Engineering Science, vol. 1, no. 1, pp. 21-32, 2007.

[4] B. Kim, V. Koncar, and C. Dufour, "Polyaniline-coated PET conductive yarns: study of electrical, mechanical, and electromechanical properties," Journal of Applied Polymer Science, vol. 101, no. 3, pp. 1252-1256, 2006.

[5] T. Tüken, B. Yazici, and M. Erbil, "Zinc modified polyaniline coating for mild steel protection," Materials Chemistry and Physics, vol. 99, no. 2-3, pp. 459-464, 2006.

[6] J.-S. Kim, S.-O. Sohn, and J.-S. Huh, "Fabrication and sensing behavior of PVF2 coated-polyaniline sensor for volatile organic compounds," Sensors and Actuators B, vol. 108, no. 12, pp. 409-413, 2005.

[7] X. He and G. Shi, "Electrochemical actuator based on monolithic polypyrrole- $\mathrm{TiO}_{2}$ nanoparticle composite film," Sensors and Actuators B, vol. 115, no. 1, pp. 488-493, 2006.

[8] M. R. Abidian, D. H. Kim, and D. C. Martin, "Conductingpolymer nanotubes for controlled drug release," Advanced Materials, vol. 18, no. 4, pp. 405-409, 2006.

[9] M. Li, Y. Guo, Y. Wei, A. G. MacDiarmid, and P. I. Lelkes, "Electrospinning polyaniline-contained gelatin nanofibers for tissue engineering applications," Biomaterials, vol. 27, no. 13, pp. 2705-2715, 2006.

[10] N. Zhu, Z. Chang, P. He, and Y. Fang, "Electrochemically fabricated polyaniline nanowire-modified electrode for voltammetric detection of DNA hybridization," Electrochimica Acta, vol. 51, no. 18, pp. 3758-3762, 2006.

[11] C. R. Martin, "Membrane-based synthesis of nanomaterials," Chemistry of Materials, vol. 8, no. 8, pp. 1739-1746, 1996.

[12] M. Steinhart, J. H. Wendorff, A. Greiner et al., "Polymer nanotubes by wetting of ordered porous templates," Science, vol. 296, no. 5575, p. 1997, 2002.

[13] J. Huang and R. B. Kaner, "Nanofiber formation in the chemical polymerization of aniline: a mechanistic study," Angewandte Chemie International Edition, vol. 43, no. 43, pp. 58175821, 2004.

[14] Z. Zhang, Z. Wei, and M. Wan, "Nanostructures of polyaniline doped with inorganic acids," Macromolecules, vol. 35, no. 15, pp. 5937-5942, 2002.

[15] I. D. Norris, M. M. Shaker, F. K. Ko, and A. G. MacDiarmid, "Electrostatic fabrication of ultrafine conducting fibers: polyaniline/polyethylene oxide blends," Synthetic Metals, vol. 114, no. 2, pp. 109-114, 2000.

[16] D. H. Reneker and I. Chun, "Nanometre diameter fibres of polymer, produced by electrospinning," Nanotechnology, vol. 7, no. 3, pp. 216-223, 1996.

[17] S. Xing, H. Zheng, and G. Zhao, "Preparation of polyaniline nanofibers via a novel interfacial polymerization method," Synthetic Metals, vol. 158, no. 1-2, pp. 59-63, 2008.

[18] J. Huang, S. Virji, B. H. Weiller, and R. B. Kaner, "Nanostructured polyaniline sensors," Chemistry, vol. 10, no. 6, pp. 13141319, 2004.

[19] N. Nuraje, K. Su, N. I. Yang, and H. Matsui, "Liquid/liquid interfacial polymerization to grow single crystalline nanoneedles of various conducting polymers," ACS Nano, vol. 2, no. 3, pp. 502-506, 2008.
[20] J. Huang, S. Virji, B. H. Weiller, and R. B. Kaner, "Polyaniline nanofibers: facile synthesis and chemical sensors," Journal of the American Chemical Society, vol. 125, no. 2, pp. 314-315, 2003.

[21] S. Liu, K. Zhu, Y. Zhang, and J. Xu, "Cyclic polyaniline nanostructures from aqueous/organic interfacial polymerization induced by polyacrylic acid," Polymer, vol. 47, no. 22, pp. 7680-7683, 2006.

[22] G. Barbarella, M. Melucci, and G. Sotgiu, "The versatile thiophene: an overview of recent research on thiophene-based materials," Advanced Materials, vol. 17, no. 13, pp. 1581-1593, 2005.

[23] S. Gronowitz, Ed., Thiophene and Its Derivatives, Part Five, vol. 44 of Chemistry of Heterocyclic Compounds: A Series of Monographs, John Wiley \& Sons, 1992.

[24] L. Zhang and M. Wan, "Chiral polyaniline nanotubes synthesized via a self-assembly process," Thin Solid Films, vol. 477, no. 1-2, pp. 24-31, 2005.

[25] W. Luzny and E. Bańka, "Relations between the structure and electric conductivity of polyaniline protonated with camphorsulfonic acid," Macromolecules, vol. 33, no. 2, pp. 425-429, 2000.

[26] M. Jayakannan, S. Annu, and S. Ramalekshmi, "Structural effects of dopants and polymerization methodologies on the solid-state ordering and morphology of polyaniline," Journal of Polymer Science, Part B, vol. 43, no. 11, pp. 1321-1331, 2005.

[27] L. Zhang and M. Wan, "Synthesis and characterization of self-assembled polyaniline nanotubes doped with D-10camphorsulfonic acid," Nanotechnology, vol. 13, no. 6, pp. 750-755, 2002.

[28] V. R. Thalladi, T. Smolka, R. Boese, and R. Sustmann, "Reproducible phenazine molecular stacks," CrystEngComm, vol. 2, pp. 96-101, 2000.

[29] L. Zhang, M. Wan, and Y. Wei, "Nanoscaled polyaniline fibers prepared by ferric chloride as an oxidant," Macromolecular Rapid Communications, vol. 27, no. 5, pp. 366-371, 2006.

[30] S. A. Chen and H. T. Lee, "Structure and properties of poly(acrylic acid)-doped polyaniline," Macromolecules, vol. 28, no. 8, pp. 2858-2866, 1995.

[31] W. Zheng, M. Angelopoulos, A. J. Epstein, and A. G. MacDiarmid, "Experimental evidence for hydrogen bonding in polyaniline: mechanism of aggregate formation and dependency on oxidation state," Macromolecules, vol. 30, no. 10, pp. 2953-2955, 1997.

[32] M. Trchová, I. Šeděnková, E. N. Konyushenko, J. S.P. Holler, and G. Ćirić-Marjanović, "Evolution of polyaniline nanotubes: the oxidation of aniline in water," Journal of Physical Chemistry B, vol. 110, no. 19, pp. 9461-9468, 2006.

[33] B. J. Kim, S. G. Oh, M. G. Han, and S. S. Im, "Preparation of polyaniline nanoparticles in micellar solutions as polymerization medium," Langmuir, vol. 16, no. 14, pp. 5841-5845, 2000.

[34] J. Laska and J. Widlarz, "Spectroscopic and structural characterization of low molecular weight fractions of polyaniline," Polymer, vol. 46, no. 5, pp. 1485-1495, 2005.

[35] I. Sapurina, M. Mokeev, V. Lavrentev et al., "Polyaniline complex with fullerene C60," European Polymer Journal, vol. 36, no. 11, pp. 2321-2326, 2000.

[36] B. Z. Zhang and X. Y. Zhao, "Synthesis, characterization, and photochromic behaviors of polythiophene derivatives in the solid state," Journal of Materials Science, vol. 44, no. 11, pp. 2765-2773, 2009. 
[37] E. C. Venancio, P. C. Wang, and A. G. MacDiarmid, "The azanes: a class of material incorporating nano/micro selfassembled hollow spheres obtained by aqueous oxidative polymerization of aniline," Synthetic Metals, vol. 156, no. 5-6, pp. 357-369, 2006.

[38] Y. Fu and R. L. Elsenbaumer, "Thermochemistry and kinetics of chemical polymerization of aniline determined by solution calorimetry," Chemistry of Materials, vol. 6, no. 5, pp. 671-677, 1994.

[39] D. S. Lin, C. T. Chou, Y. W. Chen, K. T. Kuo, and S. M. Yang, "Electrochemical behaviors of polyaniline-poly(styrenesulfonic acid) complexes and related films," Journal of Applied Polymer Science, vol. 100, no. 5, pp. 4023-4044, 2006.

[40] J. Travas-Sejdic, R. Soman, and H. Peng, "Self-assembled polyaniline thin films: comparison of poly(styrene sulphonate) and oligonucleotide as a polyanion," Thin Solid Films, vol. 497, no. 1-2, pp. 96-102, 2006.

[41] D. Gonçalves, D. S. Dos Santos, L. H. C. Mattoso, F. E. Karasz, L. Akcelrud, and R. M. Faria, "Poly(o-methoxyaniline): solubility, deprotonation-protonation process in solution and cast films," Synthetic Metals, vol. 90, no. 1, pp. 5-11, 1997.

[42] C. Weidlich, K. M. Mangold, and K. Jüttner, "EQCM study of the ion exchange behaviour of polypyrrole with different counterions in different electrolytes," Electrochimica Acta, vol. 50, no. 7-8, pp. 1547-1552, 2005.

[43] J. Huang and R. B. Kaner, Chemical Communications, Cambridge, UK, 2006.

[44] J. Huang and R. B. Kaner, "A general chemical route to polyaniline nanofibers," Journal of the American Chemical Society, vol. 126, no. 3, pp. 851-855, 2004. 

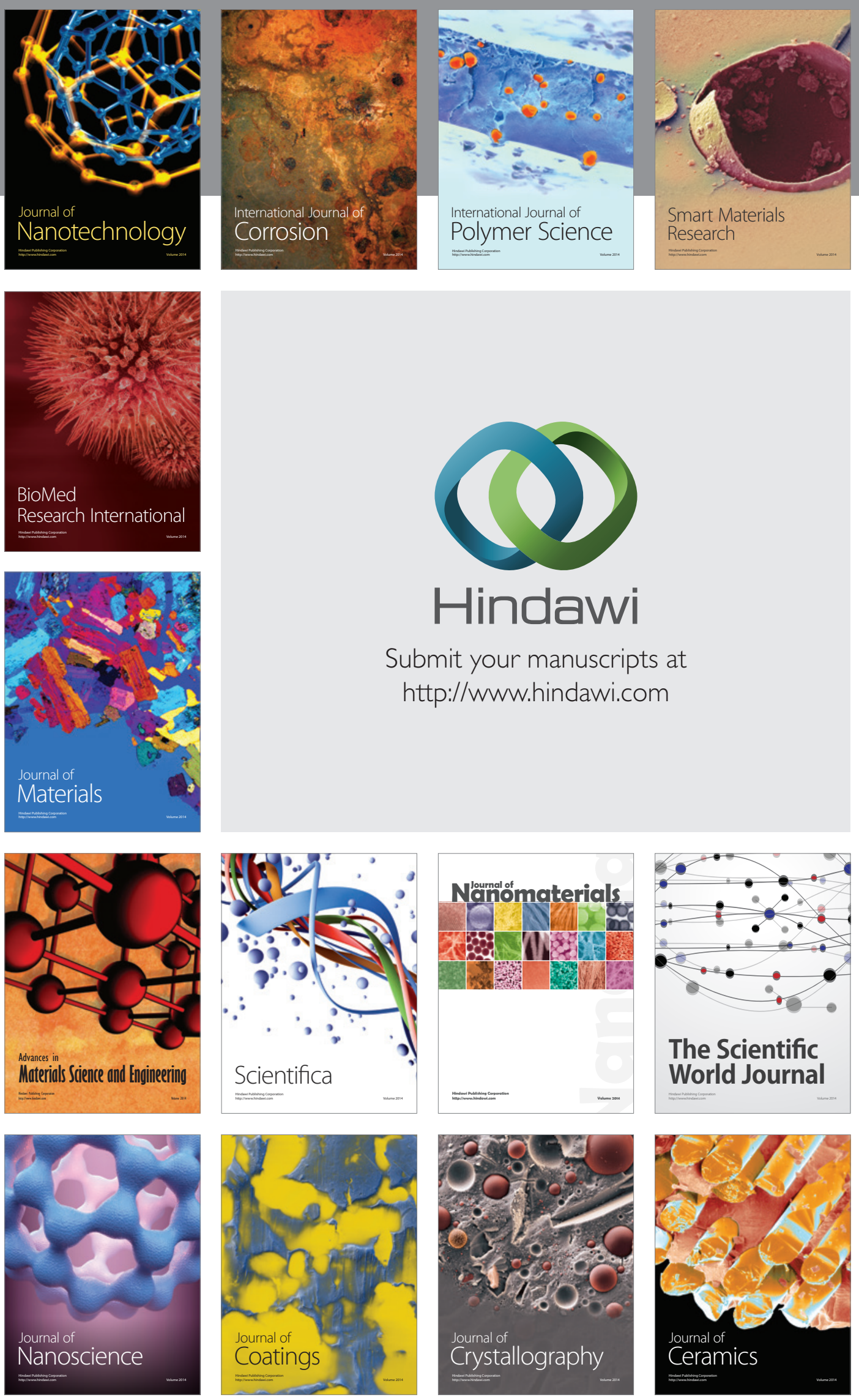

The Scientific World Journal

Submit your manuscripts at

http://www.hindawi.com

\section{World Journal}

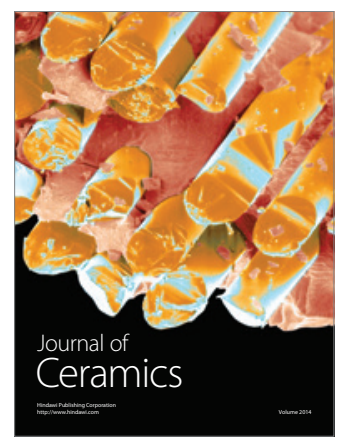

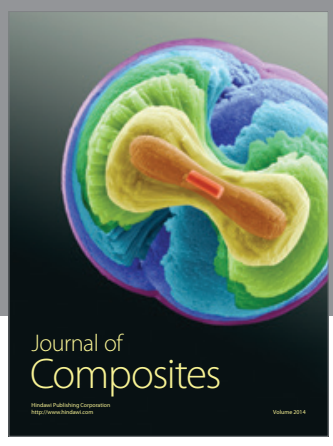
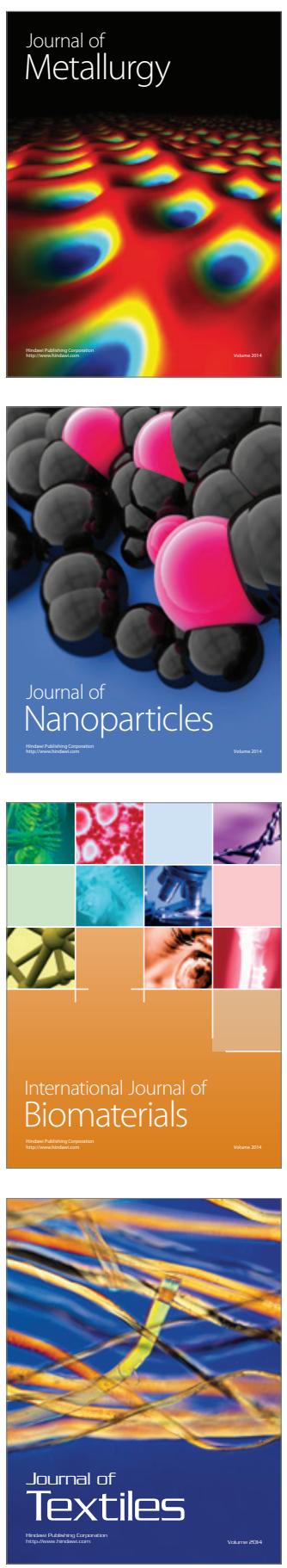